\title{
Hydrogenolysis of 2-Tosyloxy-1,3-propanediol into 1,3-Propanediol over Raney Ni Catalyst
}

\author{
Zhi Zheng, Jianli Wang, * Zhen Lu, Min Luo, Miao Zhang, Lixin Xu and Jianbing Ji \\ Zhejiang Province Key Laboratory of Biofuel, The State Key Laboratory Breeding Base of Green \\ Chemistry-Synthesis Technology, Zhejiang University of Technology, Hangzhou 310014, P. R. China
}

\begin{abstract}
2-Tosiloxi-1,3-propanodiol (TPD), um potencial precursor para produção de 1,3-propanodiol (1,3-PD), é produzido através da tosilação do glicerol com a ajuda de uma técnica de proteção de grupos. Neste trabalho, discutiu-se a hidrogenólise do TPD em 1,3-PD sobre catalisador de Raney Ni através de diferentes parâmetros de reação para otimizar as condições de reação para formação seletiva do 1,3-PD. O mecanismo de hidrogenólise do TPD e reações laterais também foram confirmados pela técnica de cromatografia em fase gasosa acoplada à espectrometria de massas (GC-MS).
\end{abstract}

2-Tosyloxy-1,3-propanediol (TPD), a potential precursor for 1,3-propanediol (1,3-PD) production, is produced by the tosylation of glycerol with the help of protecting group techniques. In this work, the hydrogenolysis of TPD into 1,3-PD over Raney Ni catalyst is discussed at different reaction parameters to optimize the reaction conditions for selective formation of 1,3-PD. The mechanisms of the hydrogenolysis of TPD and the side reactions were also confirmed by gas chromatography-mass spectrometry (GC-MS) technique.

Keywords: glycerol, 2-tosyloxy-1,3-propanediol, 1,3-propanediol, hydrogenolysis, Raney Ni

\section{Introduction}

Glycerol, a promising biomass-derived compound, is available as a major byproduct ( $10 \%$ in weight) in the manufacturing of biodiesel. ${ }^{1-3}$ Because of the recent escalating production and the utilization of biodiesel worldwide, large quantities of glycerol have been produced. ${ }^{4,5}$ The rich availability makes it an important raw material for the manufacture of some valuable chemicals (diols, epoxides, esters, ethers, etc.), thereby facilitating the replacement of petroleum-based products, and also benefiting the emerging biodiesel industry. ${ }^{6-8}$

1,3-Propanediol (1,3-PD), currently produced from petroleum derivatives, such as ethylene oxide (Shell route) or acrolein (Degussa-DuPont route), is an important precursor for the synthesis of polymethylene terephthalate and polyurethanes. ${ }^{8}$ Recent advances in the hydrogenolysis of glycerol into 1,3-PD have produced a range of possible hydrogenolysis products, such as 1,3-PD, 1,2-propanediol (1,2-PD), 1-propanol (1-PrOH), 2-propanol (2-PrOH), and some other degradation products (ethylene glycerol, ethanol, methanol and methane), but few catalysts are

*e-mail: wangjl@zjut.edu.cn selective for 1,3-PD. ${ }^{9-14}$ Kurosaka et al. ${ }^{11}$ found that the yield of 1,3-PD was up to $24 \%$ by the hydrogenolysis of glycerol over $\mathrm{Pt} / \mathrm{WO}_{3} / \mathrm{ZrO}_{2}$ catalyst. Most recently, Nakagawa et al. ${ }^{13}$ made a break through when they obtained $38 \%$ yield of 1,3-PD by running the reaction using $\mathrm{Ir}-\mathrm{ReO}_{\mathrm{x}} / \mathrm{SiO}_{2}$ as a catalyst.

The hydrogenolysis of glycerol might proceed through different pathways, depending on whether the primary or secondary hydroxyl is more easily reduced (Scheme 1). ${ }^{10}$ Because of the glycerol molecule with hydroxyl groups of similar reactivity, it is difficult to produce the desired 1,3-PD in a high selectivity. 2-Tosyloxy-1,3-propanediol (TPD), a potential precursor for the production of 1,3-PD, is produced by the tosylation of glycerol with the help of a group protection technique (acetalization). ${ }^{15-17}$ Compared with hydroxyl group, the tosyloxyl group is a better living group, and is easier to be replaced with a hydride ion. Therefore, 1,3-PD can be obtained in a high selectivity by the subsequent removal of the tosyloxyl group of TPD (Scheme 2). In this work, instead of expensive reducing reagent lithium hydride, the detosyloxylation of TPD was carried out by catalytic hydrogenolysis over the non-expensive Raney Ni catalyst, and studied at different reaction parameters to optimize the reaction conditions for selective formation of 1,3-PD. 


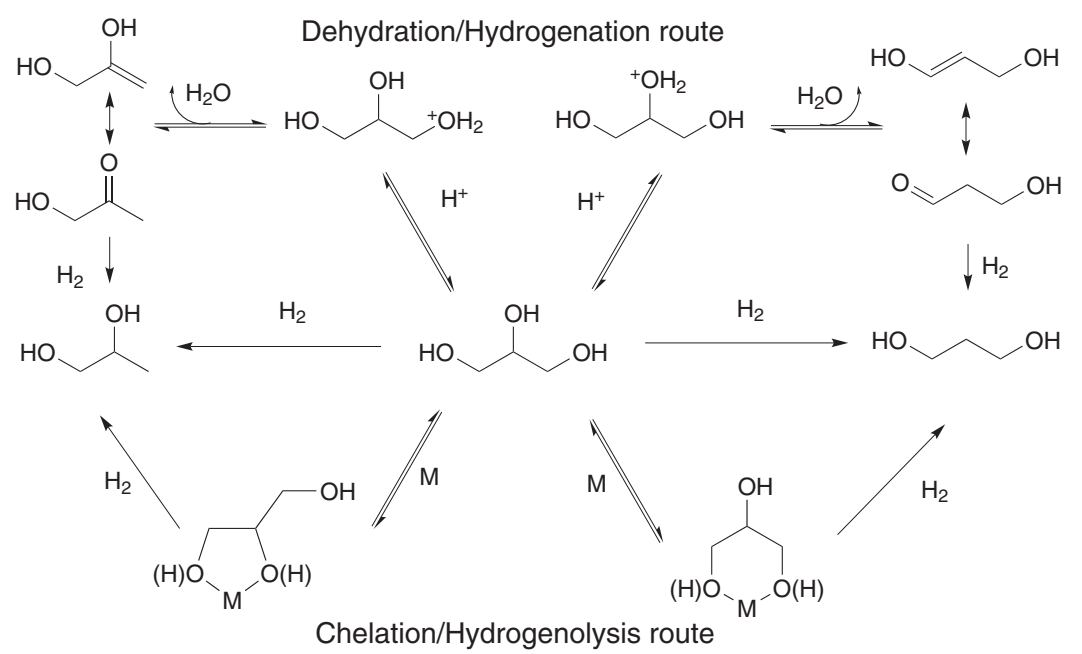

Scheme 1. Illustration of the pathways of glycerol hydrogenolysis (adapted from reference 10).

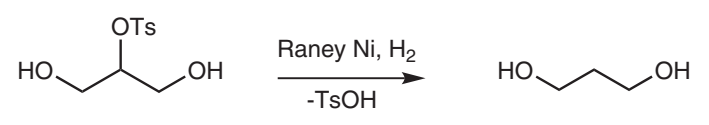

2-tosyloxy-1,3-propanediol (TPD) 1,3-propanediol (1,3-PD)
$2 \mathrm{H}, J 8.1 \mathrm{~Hz}), 4.56$ (p, 1H, J 4.7 Hz), $3.78(\mathrm{~m}, 4 \mathrm{H}), 2.80$ (s, 2H, OH), 2.44 (s, 3H); ${ }^{13} \mathrm{C}$ NMR (125 MHz, $\mathrm{CDCl}_{3}$ ) $\delta / \mathrm{ppm} 145.2,133.1,130.0,127.9,82.7,61.1,21.6$.

Hydrogenolysis of TPD

The hydrogenolysis of TPD was carried out in a $200 \mathrm{~mL}$ stainless steel autoclave. The autoclave was charged with $100 \mathrm{~mL}$ TPD dioxane solution (2 wt.\%), 0.32-0.96 g Raney Ni. After being sealed and purged repeatedly with $2 \mathrm{MPa} \mathrm{H}_{2}$ to eliminate air, the autoclave was heated to the required temperature and then pressurized with $\mathrm{H}_{2}$ to a given value. The stirring speed was set constant at $750 \mathrm{rpm}$. The reactions were conducted at the following conditions: $110-150{ }^{\circ} \mathrm{C}$, 0.4-4 $\mathrm{MPa} \mathrm{H}_{2}, 2-8 \mathrm{~h}$. After reaction, the autoclave was cooled to room temperature. The products were analyzed by gas chromatograph, (GC, Shimadzu GC-17A, HP-FFAP $30 \mathrm{~m} \times 0.25 \mathrm{~mm} \times 0.25 \mu \mathrm{m}$, flame ionization detector), and identified by gas chromatography-mass spectrometry (GC-MS, Agilent 7890A/5875C, HP-5SM $30 \mathrm{~m} \times 0.25 \mathrm{~mm} \times 0.25 \mu \mathrm{m})$. Quantifications were achieved by using 1,4-butanediol as an internal standard. The unreacted TPD was confirmed by high performance liquid chromatography (HPLC, Varian Prostar 210, kromasil 100-5 $\mathrm{C}_{18}$ column: $\Phi 4.6 \mathrm{~mm} \times 250 \mathrm{~mm}$, UV-Vis detector).

\section{Results and Discussion}

\section{Reaction scheme and product identification}

The hydrogenolysis of glycerol is suggested to proceed via dehydration of glycerol into acetol and 3-hydroxypropanal (3-HPA) intermediate, and followed by 
the subsequent hydrogenation to produce the corresponding 1,2-PD and 1,3-PD, respectively. ${ }^{9-14,19,20}$ Hence, as shown in Scheme 3, the selective transformation of glycerol to $1,3-\mathrm{PD}$ requires a catalyst system with the ability to not only promote the coupled glycerol dehydration (equilibria: $\mathrm{K}_{\text {glycerol dehydration }}$ )/3-HPA hydrogenation (equilibria: $\mathrm{K}_{\text {diol }}$ ) reactions, but also minimize the 3-HPA dehydration (equilibria: $\mathrm{K}_{\mathrm{eq}}$ ). However, as stated by Taher et al. ${ }^{19}$ the activation barrier of initial dehydration of glycerol was much higher than the dehydration/ hydrogenation of 3-HPA, that is:

$\Delta \mathrm{G}^{\ddagger}\left(\mathrm{K}_{\text {glycerol dehydration }}\right) \gg \Delta \mathrm{G}^{\ddagger}\left(\mathrm{K}_{\text {diol }}\right)>\Delta \mathrm{G}^{\ddagger}\left(\mathrm{K}_{\mathrm{eq}}\right)$.

To overcome the $\Delta \mathrm{G}^{\ddagger}\left(\mathrm{K}_{\text {glycerol dehydration }}\right)$, the dehydration of 3-HPA to acrolein (AO) is highly favored at higher temperature $\left(>175^{\circ} \mathrm{C}\right)$.

In our investigation, by using GC-MS as a qualitative assay, the dominative TPD hydrogenolysis products were 1,3-PD and 1-PrOH. Based on these proposed mechanism of 1,3-PD formation in glycerol hydrogenolysis, ${ }^{19-23}$ the hydrogenolysis of TPD might occur as shown in Scheme 3. TPD undergoes a detosyloxylation to give 3-HPA and TsOH, the subsequent reaction of 3-HPA proceed via the following routes: $(i)$ hydrogenation of 3-HPA to produce 1,3-PD, and (ii) dehydration of 3-HPA to form AO intermediate, and followed by the subsequent hydrogenation to produce 1-PrOH. Compared with the hydroxyl group of glycerol, the tosyloxyl group of TPD is a better living group, and can easily undergo a detosyloxylation to give the exclusive
3-HPA at low temperature (ca. $100-140{ }^{\circ} \mathrm{C}$ ). This means that the activation barrier

$\Delta \mathrm{G}^{\ddagger}\left(\mathrm{K}_{\text {glycerol dehydration }}\right) » \Delta \mathrm{G}^{\ddagger}\left(\mathrm{K}_{\text {detosyloxylation }}\right)>\Delta \mathrm{G}^{\ddagger}\left(\mathrm{K}_{\text {diol }}\right)>$
$\Delta \mathrm{G}^{\ddagger}\left(\mathrm{K}_{\mathrm{eq}}\right)$,

thereby minimizing the dehydration route of the 3-HPA to produce $1-\mathrm{PrOH}$. The determination of the optimum reaction conditions of Scheme 3 for selective formation of 1,3-PD, therefore, mainly depends on the adjustment of two equilibria of 3-HPA/AO $\left(\mathrm{K}_{\mathrm{eq}}\right)$ and 3-HPA/1,3-PD $\left(\mathrm{K}_{\text {diol }}\right)$.

Moreover, with the exception of the 1,3-PD and 1-PrOH, about 15 kinds of chemicals were also separated by GC, and half of them can be possibly identified via MS by the comparison with the standard mass spectrum in the NIST data base (see MS spectra comparison in the SI section). As stated by Huang et al. ${ }^{20}$ and Schlaf et al. ${ }^{24}$ the alcohol and aldehyde can be easily condensed over acid catalysts in the hydrogenolysis of glycerol; da Silva et al. ${ }^{25}$ and Medeiros et al. ${ }^{26}$ have demonstrated that the condensation reaction between the glycerol and assorted alcohols, and the self-condensation of glycerol can be readily achieved over acid catalyst. Based on these proposed mechanism of formation, as shown in Scheme 4, in the present of $\mathrm{TsOH}$, these identified byproducts can be supposed from the following reactions: $(i)$ the decomposition of TPD to produce glycerol, and followed by the subsequent hydrogenolysis reaction, (ii) the condensation of 1,3-PD and acetaldehyde, and (iii) the self-condensation of glycerol or 1,2-PD.

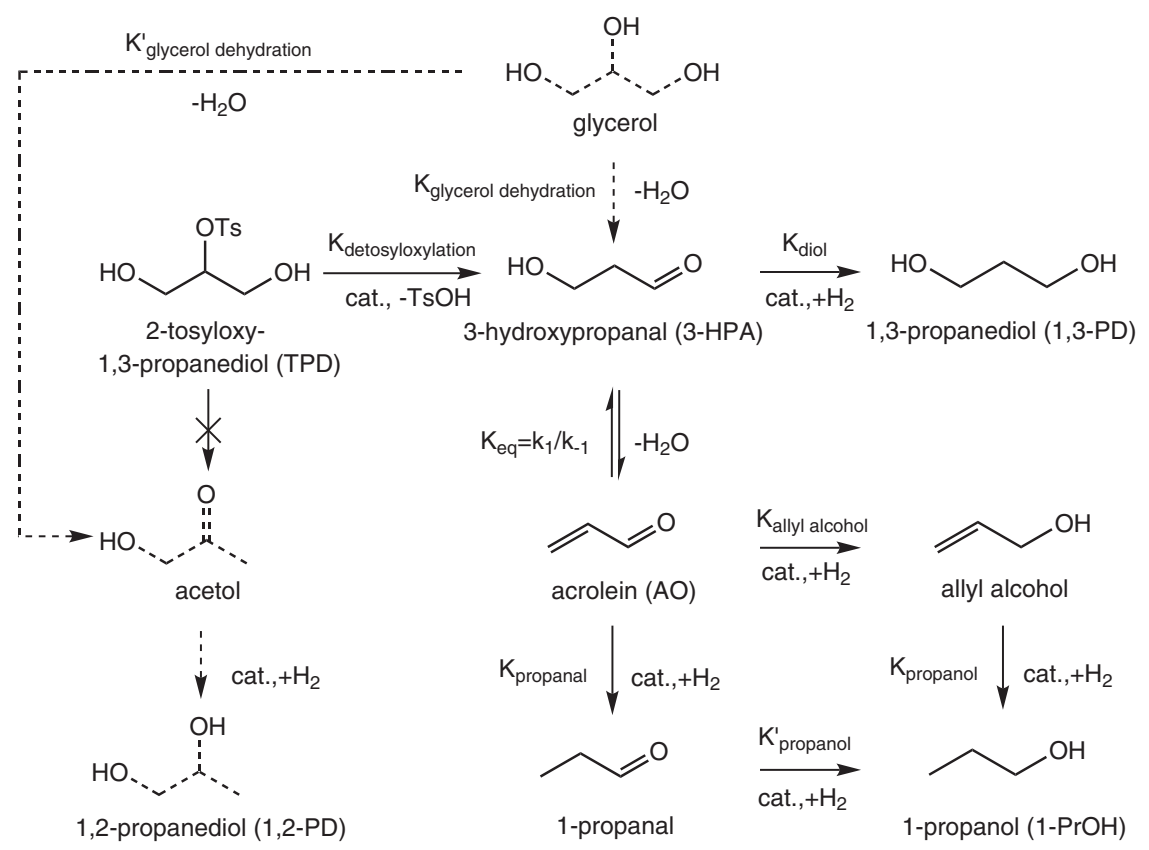

Scheme 3. The potential pathways of TPD hydrogenolysis. Adapted from references 9-14,19-23. 
$i$<smiles>CCC(CO)C(O)CO</smiles>

ii

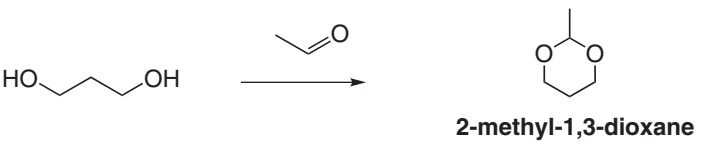

iii<smiles>OCC(O)CO</smiles><smiles>OCC1COCC(CO)O1</smiles><smiles>OCC1COC(CO)CO1</smiles>

(1,4-dioxane-2,6-diyl)dimethanol

(1,4-dioxane-2,5-diyl)dimethanol<smiles>OCC(O)COCC(O)CO</smiles>

3,3'-oxydipropane-1,2-diol<smiles>CC(O)CO</smiles><smiles>CC(O)COCC(C)O</smiles>

1,1'-oxydipropan-2-ol

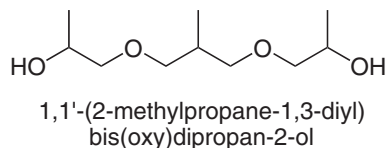

Scheme 4. The potential side reactions of TPD hydrogenolysis (the products identified via GC-MS were highlighted in bold). Adapted from references $20,24-26$.

\section{Effect of reaction temperature}

Figure 1 shows the effect of temperature on TPD conversion and product selectivity. As the temperature elevated from 110 to $150{ }^{\circ} \mathrm{C}$, there was a proportional increase in TPD conversion from 16.7 to $84.1 \%$. The selectivity of 1,3-PD increased until $140{ }^{\circ} \mathrm{C}$ and began to decrease from 57.1 to $55.2 \%$, as the temperature further elevated to $150{ }^{\circ} \mathrm{C}$. Conversely, when the temperature was above $140{ }^{\circ} \mathrm{C}$, the selectivity of $1-\mathrm{PrOH}$ increased from 24.8 to $42.7 \%$. It is to prove that the dehydration of 3-HPA to form $\mathrm{AO}$ is highly favored at high temperature $\left(>140{ }^{\circ} \mathrm{C}\right)$ to drive the reaction towards the side of $1-\mathrm{PrOH}$ formation. As stated in Huang et al.,${ }^{20}$ it was found a similar conclusion that high operating temperature $\left(180-230{ }^{\circ} \mathrm{C}\right)$ resulted in low selectivity of 1,3-PD (25-13\%).

\section{Effect of catalyst weight}

Figure 2 provides the effect of catalyst weight on TPD hydrogenolysis. The conversion of TPD increased obviously within the catalyst weight range of 0.32-0.96 g. In the absence of Raney $\mathrm{Ni}$, TPD was found to be inactive at $140{ }^{\circ} \mathrm{C}$, indicating that the function of Raney $\mathrm{Ni}$ is not only limited to 3-HPA and AO hydrogenation, but also involved in detosyloxylation step as well. The selectivity of 1,3-PD increased from 57.1 to $73.9 \%$ with the increasing

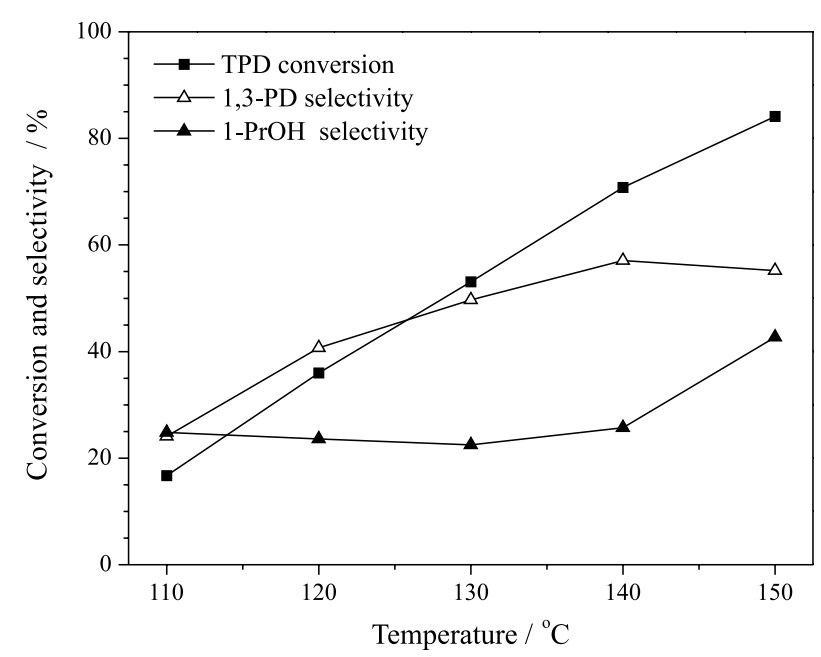

Figure 1. The effect of temperature on TPD hydrogenolysis (2 wt.\% of TPD in dioxane, $3 \mathrm{MPa} \mathrm{H}_{2}, 0.32 \mathrm{~g}$ Raney Ni, 4 h).

catalyst weight from 0.32 to $0.80 \mathrm{~g}$, and slowly increased to $74.5 \%$ as the catalyst weight further increased to $0.96 \mathrm{~g}$. Conversely, the selectivity towards $1-\mathrm{PrOH}$ presented a distinct decrease (25.6-15.0\%) within the catalyst weight range of $0.32-0.80 \mathrm{~g}$. It is to validate the hypothesis that, as illustrated in Scheme 3, the 1,3-PD and 1-PrOH are formed in parallel, and the selectivity of 1,3-PD and 1-PrOH can be controlled by the relative hydrogenation/dehydration rate of 3-HPA. Thus, increasing Raney Ni weight can fasten the hydrogenation rate of 3-HPA and the selectivity of 
1,3-PD increased correspondingly. Opposite to the work presented by Dasari et al. ${ }^{27}$ the excess catalyst did not further promote the excessive hydrogenolysis of 1,3-PD to lower alcohol and gas.

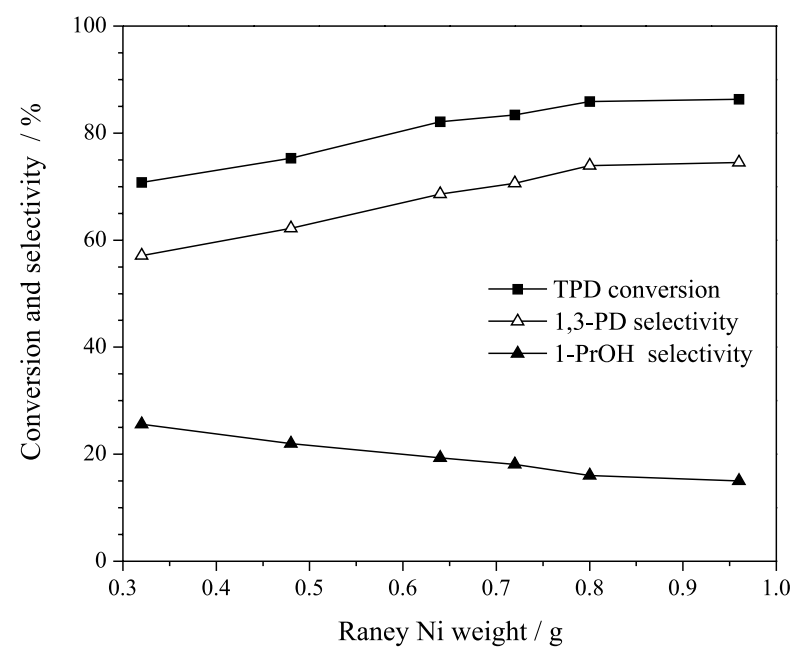

Figure 2. The effect of Raney Ni weight on TPD hydrogenolysis (2 wt.\% of TPD in dioxane, $140{ }^{\circ} \mathrm{C}, 3 \mathrm{MPa} \mathrm{H}_{2}, 4 \mathrm{~h}$ ).

\section{Effect of hydrogen pressure}

Figure 3 summaries the TPD conversion and product selectivity at different $\mathrm{H}_{2}$ pressure. The conversion of TPD was independent with $\mathrm{H}_{2}$ pressure. Enhancing the $\mathrm{H}_{2}$ pressure from 0.4 to $1.0 \mathrm{MPa}$ lead to an increase in the selectivity of 1,3-PD from 63.6 to $74.0 \%$, whereas the selectivity of 1-PrOH declined from 17.8 to $15.0 \%$. These results imply that the high $\mathrm{H}_{2}$ pressure could fasten the hydrogenation rate of 3-HPA, and drive the reaction equilibrium towards 1,3-PD formation. As the $\mathrm{H}_{2}$ pressure further enhanced from 1.0 to 4.0 MPa, there was no further increase in the selectivity of 1,3-PD (74.0-73.9\%), and the excess $\mathrm{H}_{2}$ pressure did not cause considerable change in the selectivity of 1-PrOH either, suggesting that 1-PrOH is produced through the dehydration of 3-HPA rather than the excessive hydrogenolysis of 1,3-PD. To validate this speculation, the hydrogenolysis of 1,3-PD was carried out in dioxane at $140{ }^{\circ} \mathrm{C}$ under 5.0 $\mathrm{MPa} \mathrm{H}_{2}$, after reaction for $4 \mathrm{~h}$, the conversion of 1,3-PD was low, no $n$-PrOH was produced (Figure S12 in the SI section).

\section{Effect of reaction time}

The effect of reaction time on TPD conversion and product selectivity was studied, and the results are tabulated in Figure 4. With the reaction time prolonged from 2 to $8 \mathrm{~h}$, the conversion of TPD increased from 67.8 to $91.2 \%$, meanwhile the selectivity of 1,3 -PD raised from 76.7 to

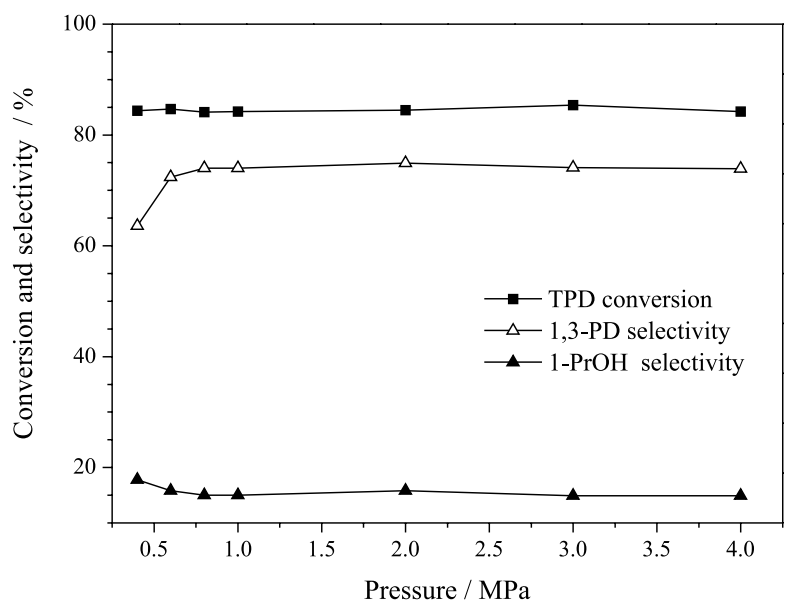

Figure 3. The effect of hydrogen pressure on TPD hydrogenolysis ( $2 \mathrm{wt} . \%$ of TPD in dioxane, $140{ }^{\circ} \mathrm{C}, 0.8 \mathrm{~g}$ Raney Ni, 0.4-4 $\mathrm{MPa} \mathrm{H}_{2}, 4$ h).

$81.0 \%$, and the selectivity of 1-PrOH slightly increased from 14.4 to $16.2 \%$. Opposite observations were reported in the literature, ${ }^{28-31}$ it was observed that the low selectivity of 1,3-PD formation in glycerol hydrogenolysis could be contributed to the high reactivity of 1,3-PD in water medium catalyzed by $\mathrm{Ru} / \mathrm{C}+$ Amberlyst, and most 1,3-PD (77.7\%) was further hydrogenolysed into 1-PrOH and ethanol. In our experiment, after reaction for $8 \mathrm{~h}$ in dioxane, the yield of $1,3-\mathrm{PD}$ was up to $73.8 \%$ without obvious degradation.

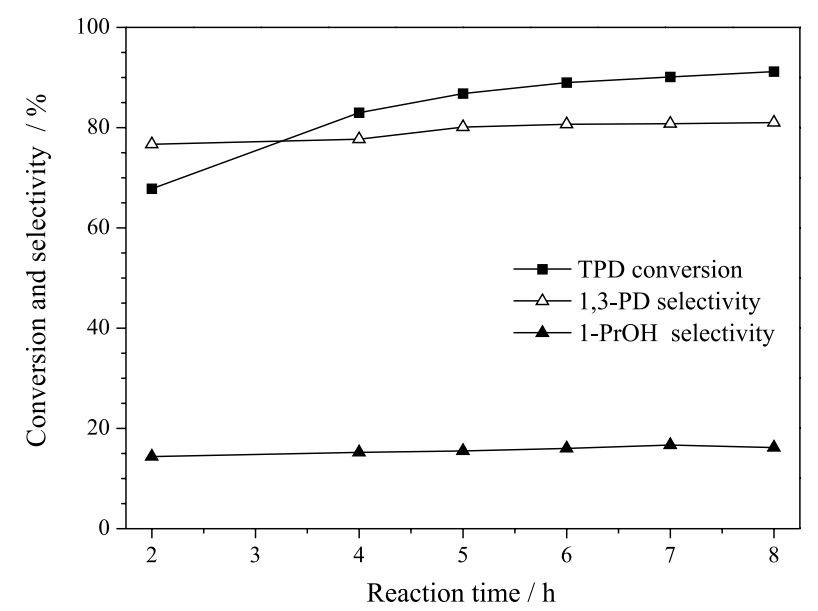

Figure 4. The effect of reaction time on TPD hydrogenolysis (2 wt.\% of TPD in dioxane, $140^{\circ} \mathrm{C}, 0.8 \mathrm{~g}$ Raney $\mathrm{Ni}, 1 \mathrm{MPa} \mathrm{H}_{2}$ ).

\section{Effect of TPD concentration}

The study was also performed in different TPD concentrations, and the results are presented in Figure 5. The conversion of TPD as well as the selectivity of 1,3-PD and 1-PrOH were kept constant within the TPD concentration range of 2-6 wt. $\%$. As TPD concentration further raised from 6 to $20 \mathrm{wt} . \%$, the conversion of TPD increased from 91.2 to $95.0 \%$, while the selectivity of 
1,3-PD decreased from 81.0 to $64.3 \%$, and the selectivity of 1-PrOH declined from 16.2 to 9.3\%. As shown in Scheme 4, the decline in the selectivity of 1,3-PD and 1-PrOH was contributed to the TPD decomposition reaction under high concentration of $\mathrm{TsOH}$, and followed by the subsequent hydrogenolysis to produce 1,2-PD and ethanol.

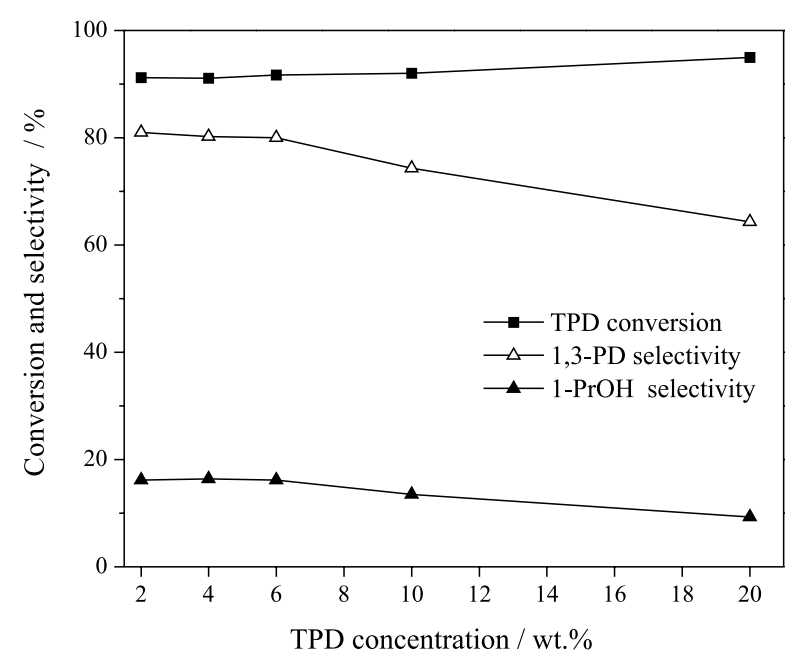

Figure 5. The effect of TPD concentration on TPD hydrogenolysis $\left(140{ }^{\circ} \mathrm{C}, 40\right.$ wt. $\%$ Raney Ni of TPD, $\left.1 \mathrm{MPa} \mathrm{H}_{2}, 8 \mathrm{~h}\right)$.

\section{Conclusions}

Selective formation of 1,3-PD via hydrogenolysis of TPD was achieved at low $\mathrm{H}_{2}$ pressure using Raney $\mathrm{Ni}$ as catalyst. Under the conditions of $140{ }^{\circ} \mathrm{C}, 1 \mathrm{MPa} \mathrm{H}_{2}$ and $8 \mathrm{~h}, 91.2 \%$ TPD conversion with $81.0 \%$ selectivity for $1,3-\mathrm{PD}$ and $16.7 \%$ selectivity for $1-\mathrm{PrOH}$ was obtained. The yield of 1,3-PD was mainly dependent on the reaction temperature, Raney Ni weight and TPD concentration. The proposed mechanism of TPD hydrogenolysis was validated. It was proved that, with the exception of $n$-PrOH formation, the TPD decomposition was another important side reaction under high concentration of TsOH. Further studies aimed at the elimination of $\mathrm{TsOH}$ by adding acid binding agent are currently underway.

\section{Supplementary Information}

Supplementary data are available free of charge at http://jbcs.sbq.org.br as PDF file.

\section{Acknowledgments}

The authors would like to thank the Science and Technology Program (No. 2008C21025) and Natural Science Foundation (Y4080530) of Zhejiang Province, P. R. China, for financial support.

\section{References}

1. Pinto,A. C.; Guarieiro, L. L. N.; Rezende, M. J.C.; Ribeiro, N. M.; Torres, E. A.; Lopes, W. A.; Pereira, P. A. D.; de Andrade, J. B.; J. Braz. Chem. Soc. 2005, 16, 1313.

2. Faria, E. A.; Marques, J. S.; Dias, I. M.; Andrade, R. D. A.; Suarez, P. A. Z.; Prado, A. G. S.; J. Braz. Chem. Soc. 2009, 20, 1732.

3. Ji, J. B.; Wang, J. L.; Li, Y. C.; Yu, Y. L.; Xu, Z. C.; Ultrasonics 2006, 44, E411.

4. Luo M.; Zhang, R.Y.; Zheng, Z.; Wang, J. L.; Ji, J. B.; J. Braz. Chem. Soc. 2012, 23, 241.

5. Johnsona, D. T.; Taconib, K. A.; Environ. Prog. 2007, 26, 338.

6. Pagliaro, M.; Ciriminna, R.; Kimura, H.; Rossi, M.; Pina, C. D.; Angew. Chem., Int. Ed. 2007, 46, 4434.

7. Behr, A.; Eilting, J.; Irawadi, K.; Leschinski, J.; Lindner, F.; Green Chem. 2008, 10, 13.

8. Zhou, C. H.; Beltramini, J. N.; Fan, Y. X.; Lu, G. Q.; Chem. Soc. Rev. 2008, 37, 527.

9. Schlaf, M.; Ghosh, P.; Fagan, P. J.; Hauptman, E.; Bullock, R. M.; Angew. Chem., Int. Ed. 2001, 40, 3887.

10. Chaminand, J.; Djakovitch, L.; Gallezot, P.; Marion, P.; Pinel, C.; Rosier, C.; Green Chem. 2004, 6, 359.

11. Kurosaka, T.; Maruyama, H.; Naribayashi, I.; Sasaki, Y.; Catal. Commun. 2008, 9, 1360.

12. Shinmi, Y.; Koso, S.; Kubota, T.; Nakagawa, Y.; Tomishige, K.; Appl. Catal., B 2010, 94, 318.

13. Nakagawa, Y.; Shinmi, Y.; Koso, S.; Tomishige, K.; J. Catal. 2010, 272, 191.

14. Gong, L. F.; Lu, Y.; Ding, Y. J.; Lin, R. H.; Li, J. W.; Dong, W. D.; Wang, T.; Chen, W. M.; Appl. Catal., A 2010, 390, 119.

15. Zheng, Z.; Luo, M.; Yu, J. E.; Wang, J. L.; Ji, J. B.; Ind. Eng. Chem. Res. 2012, 51, 3715.

16. Deutsch, J.; Martin, A.; Lieske, H.; J. Catal. 2007, 245, 428.

17. Wang, K.; Hawley, M. C.; DeAthos, S. J.; Ind. Eng. Chem. Res. 2003, 42, 2913.

18. Juaristi, E.; Antúnez, S.; Tetrahedron 1992, 48, 5941.

19. Taher, D.; Thibault, M.E.; Di Mondo, D.; Jennings, M.; Schlaf, M.; Chem. Eur. J. 2009, 15, 10132.

20. Huang, L.; Zhu, Y. L.; Zheng, H. Y.; Ding, G. Q.; Li, Y. W.; Catal. Lett. 2009, 131, 312.

21. Zhu, X. D.; Valerius G.; Hofmann, H.; Haas, T.; Arntz, D.; Ind. Eng. Chem. Res. 1997, 36, 2897.

22. Zhu, X. D.; Valerius, G.; Hofmann, H.; Chem. Eng. Process. 1996, 35, 495.

23. Zhu, X.; Hofmann, H.; AIChE J. 1997, 43, 475.

24. Schlaf, M; Dalton Trans. 2006, 394, 645.

25. da Silva, C. R. B.; Gonçalves, V. L. C.; Lachter, E. R.; Mota, C. J. A.; J. Braz. Chem. Soc. 2009, 20, 201.

26. Medeiros, M. A.; Araujo, M. H.; Augusti, R.; de Oliveira, L. C. A.; Lago, R. M.; J. Braz. Chem. Soc. 2009, 20, 1667. 
27. Dasari, M. A.; Kiatsimkul, P. P.; Sutterlin, W. R.; Suppes, G. J.; Appl. Catal., A 2005, 281, 225.

28. Kusunoki, Y.; Miyazawa, T.; Kunimori, K.; Tomishige, K.; Catal. Commun. 2005, 6, 645.

29. Miyazawa, T.; Kusunoki, Y.; Kunimori, K.; Tomishige, K.; J. Catal. 2006, 240, 213.
30. Furikado, I.; Miyazawa, T.; Koso, S.; Shimao, A.; Kunimori, K.; Tomishige, K.; Green Chem. 2007, 9, 582.

31. Miyazawa, T.; Koso, S.; Kunimori, K.; Tomishige, K.; Appl. Catal., A 2007, 329, 30.

Submitted: March 29, 2012

Published online: February 27, 2013 